\title{
The Regulatory System in Europe with Special Emphasis on Allergen Products
}

\author{
A.R. Lorenz D. Lüttkopf R. Seitz S. Vieths \\ Division of Allergology, Paul-Ehrlich-Institut, Langen, Germany
}

\section{Key Words}

Regulatory affairs $\cdot$ Allergen products $\cdot$ Marketing

authorisation $\cdot$ Medicinal products

\begin{abstract}
For each medicinal product quality, safety and efficacy have to be proven to obtain a marketing authorisation. The national competent health authorities and the European Medicines Agency (EMEA) with support of the Heads of Medicines Agencies (HMA) work together to grant marketing authorisations for medicinal products. Several regulatory procedures to apply for a marketing authorisation in the European Community (EC) and associated countries exist. After approval by a national procedure a medicinal product can be marketed in only one country. If a medicinal product should enter the markets of two or more European countries of choice the application has to undergo the Mutual Recognition Procedure (MRP) or the Decentralised Procedure (DCP). A marketing authorisation granted by the Centralised Procedure (CP) is valid in the whole EC. The CP is mandatory for certain medicinal products, for example all products derived from recombinant DNA technology including recombinant allergens. The guidance documents applicable to allergen products comprise general as well as product-specific guidelines such as the Note for Guidance on Allergen Products and the Monograph on Allergen Products of the European Pharmacopoeia. So-called 'named
\end{abstract}

patient products' have a special status and are applied to patients without having a marketing authorisation. Recombinant allergens as medicinal products are insufficiently covered by the existing allergen product-specific guidelines, but product-specific guidelines are in the development stage.

Copyright $\odot 2008$ S. Karger AG, Basel

\section{Introduction}

Europe is still in the process of leading the diversity of numerous independent nations into an increasingly integrated economic and political community. This process of harmonisation is based on several treaties starting in 1951 with the European Coal and Steel Community by the Treaty of Paris and was developed over decades into the European Union (EU) entered into force in 1993 by the Maastricht Treaty. After several enlargements currently the EU comprises 27 member states. Important elements of the EU are the political institutions European Council (i.e. assembly of member state governments, not to be mixed up with the Council of Europe), the European Parliament and the European Commission. All these three institutions have the power to produce legally binding documents on the community level as far as it is intended by the treaties (table 1) [1].

\section{KARGER}

Fax +4161306 1234

E-Mail karger@karger.ch

www.karger.com (c) 2008 S. Karger AG, Basel

$1018-2438 / 08 / 1474-0263 \$ 24.50 / 0$

Accessible online at:

www.karger.com/iaa
Correspondence to: Prof. Dr. Stefan Vieths

Division of Allergology, Paul-Ehrlich-Institut

Paul-Ehrlich-Str. 51-59, DE-63225 Langen (Germany)

Tel. +49610377 2400, Fax +49610377 1258, E-Mail viest@pei.de 
Table 1. European institutions and regulatory bodies involved in the regulation of medicinal products

\begin{tabular}{|c|c|c|c|c|}
\hline Political organisation & Institutions & \multicolumn{2}{|c|}{ Involved regulatory bodies } & Functions \\
\hline \multirow[t]{2}{*}{ European Community (EC) } & \multicolumn{3}{|l|}{$\begin{array}{l}\text { European Council } \\
\text { European Parliament } \\
\text { European Commission }\end{array}$} & - Pharmaceutical legislation as foreseen in the Treaty ${ }^{1}$ \\
\hline & \multicolumn{3}{|l|}{ European Commission } & - Granting marketing authorisation according to $\mathrm{CP}$ \\
\hline \multirow[t]{4}{*}{$\begin{array}{l}\text { European Community } \\
\text { (EC) + Norway, Iceland, } \\
\text { Liechtenstein }\end{array}$} & \multirow[t]{2}{*}{ EMEA } & \multicolumn{2}{|c|}{$\begin{array}{l}\text { CHMP and other } \\
\text { Committees, Working } \\
\text { Parties, Scientific Advisory } \\
\text { Groups and other } \\
\text { committee-associated } \\
\text { groups composed of experts } \\
\text { from the EC member states }\end{array}$} & $\begin{array}{l}\text { - Scientific opinion on marketing authorisation application during } \\
\text { a CP as basis for the decisions of the European Commission } \\
\text { - Arbitrations in MRP/DCP } \\
\text { - Scientific and technical guidance on non-clinical and clinical } \\
\text { issues } \\
\text { - Elaboration and release of regulatory documents (Note for } \\
\text { Guidance, Guideline, Points to Consider, etc.) reflecting } \\
\text { scientific state-of-the-art concerning quality, safety and efficacy } \\
\text { of medicinal products }\end{array}$ \\
\hline & & \multicolumn{2}{|l|}{ Secretariat } & $\begin{array}{l}\text { - Administrative advice } \\
\text { - Support to applicants, delegates and experts } \\
\text { - Support to CMD(h), CMD(v) }\end{array}$ \\
\hline & \multirow[t]{2}{*}{ Member states } & \multicolumn{2}{|l|}{$\begin{array}{l}\text { National competent } \\
\text { authority }\end{array}$} & $\begin{array}{l}\text { - Scientific assessment during National Procedure or } \\
\text { MRP/DCP as RMS or CMS } \\
\text { - National marketing authorisation of medicinal products } \\
\text { according to a National Procedure or MRP/DCP } \\
\text { - Contribution to evaluation boards of EMEA by experts } \\
\text { - Batch release of medicinal products }\end{array}$ \\
\hline & & \multicolumn{2}{|c|}{ HMA [CMD(h), CMD(v)] } & $\begin{array}{l}\text { - Forum for the exchange of the views of the member states and } \\
\text { communication of them with the EMEA and the European } \\
\text { Commission } \\
\text { - Technical and scientific support during MRP/DCP by CMD(h), } \\
\text { CMD(v) } \\
\text { - Release of procedural and scientific guidance documents } \\
\text { - Support to implementation of EU directives in the member } \\
\text { states }\end{array}$ \\
\hline $\begin{array}{l}\text { Council of Europe: } \\
\text { European Pharmacopoeia } \\
\text { Commission } \\
\text { (= European Community }+9 \\
\text { European and Asian states) }\end{array}$ & EDQM & PhEur & & - Collection of methods, Monographs, pharmaceutical rules \\
\hline \multicolumn{3}{|c|}{$\begin{array}{l}\quad \mathrm{CP}=\text { Centralised Procedure; EMEA = European Medicines Agency; } \\
\mathrm{CHMP}=\text { Committee for Medicinal Products for Human Use; } \mathrm{MRP}=\mathrm{Mu}- \\
\text { tual Recognition Procedure; } \mathrm{DCP}=\text { Decentralised Procedure; } \mathrm{CMD}(\mathrm{h})= \\
\text { Co-ordination Group for Mutual Recognition and Decentralised Proce- } \\
\text { dures (Human); CMD }(\mathrm{v})=\text { Co-ordination Group for Mutual Recognition } \\
\text { and Decentralised Procedures (Veterinary); RMS = Reference Member }\end{array}$} & \multicolumn{2}{|c|}{$\begin{array}{l}\text { State; CMS = Concerned Member State; HMA = Heads of Medicines } \\
\text { Agencies; EDQM = European Directorate for the Quality of Medicines; } \\
\text { PhEur = European Pharmacopoeia. } \\
{ }^{1} \text { Consolidated versions of the Treaty on European Union and of the } \\
\text { Treaty establishing the European Community. OJ (29.12.2006) C321E:1- } \\
\text { 331. }\end{array}$} \\
\hline
\end{tabular}

\section{The Regulatory System for Medicinal Products in Europe}

\section{Quality, Safety and Efficacy - The Key Criteria}

Before entering the market every medicinal product, human or veterinary, needs a marketing authorisation (MA) granted by national or European authorities [2]. A manufacturer submits a marketing authorisation application (MAA) to the competent authority/authorities consisting of preclinical and clinical data which demonstrate the quality, safety and efficacy of the medicinal product. Quality represents pharmaceutical quality with, for example, control of impurities, batch-to-batch consistency and stability. Efficacy means that the medicinal products induce the intended biological activity in patients and safety implies a positive risk-benefit balance with an acceptable rate of adverse reactions. 


\section{The Legal System}

The European Community (EC), i.e. the member states of the EU as well as the three associated EFTA (European Free Trade Association) countries Norway, Iceland and Liechtenstein, takes part in one European market for medicinal products and in the same regulatory system. In the following the term member state (MS) means all these countries participating in one common European market. The European pharmaceutical legislation for medicinal products for human and veterinary use began in 1965 with Directive 65/65/EEC which was repeatedly amended during the following years [3]. In 2001, the existing legal documents were combined and updated creating the so-called Community Code by means of Directive 2001/83/EC (medicinal products for human use) and Directive 2001/82/EC (medicinal products for veterinary use) $[2,4]$. Meanwhile these two directives have been amended several times, demonstrating that the European pharmaceutical legislation is still in dynamic evolution [5-7].

The legal framework for medicinal products comprises general as well as product-specific regulations on both the European and the national level [8]. In Europe so-called 'Regulations' are directly valid in all MS and each citizen can appeal to it [9]. 'Directives' have to be implemented in the national legislation of each MS within a certain period of time before becoming binding [2]. For example, Directive 2003/63/EC which amended Directive 2001/83/EC is particularly important concerning MA of medicinal products for human use stipulating detailed requirements for the content of the application dossier [7].

Other European regulatory documents are 'Guidelines', 'Notes for Guidance' and 'Points to Consider' providing more detailed guidance for specific medicinal products, diseases or studies to assure quality, safety and efficacy [10-13]. These documents are legally non-binding but reflect scientific state-of-the-art and have the status of strong recommendations and therefore should be followed. In rare special cases deviations may be possible but have to be justified thoroughly. EudraLex - the rules governing medicinal products in the European Union is a collection of legal documents as well as of instructive documents providing information on marketing procedures [8]. On a national level additional instructions imposing further requirements for an application dossier or the regulatory procedure may exist $[14,15]$.

The European Pharmacopoeia is a collection of pharmaceutical rules valid for substances, methods and medicinal products and is obligatory in all countries that signed the Pharmacopoeia which are the countries of the
EC, and several associated countries such as Norway, Iceland, Switzerland or Turkey. Several countries with observer status such as Australia exist [16]. The European Pharmacopoeia documents consist of monographs on medicinal products for example on allergen products describing the main characteristics and key parameters to be fulfilled and the assays to be applied. Furthermore, the European Pharmacopoeia provides general chapters on methods of pharmaceutical analysis.

\section{European Medicines Agency}

The official bodies of the regulatory system for medicinal products are the competent national health authorities and the European Medicines Agency (EMEA) located in London, UK (table 1) [17, 18]. The EMEA functions as a platform coordinating the evaluation processes in Europe and bringing together European scientists on various boards which contribute to European regulatory evaluations and establish new guidance documents $[9,18$, 19].

Different responsibilities are allocated to five committees which are the 'working arms' of the EMEA: the Committee for Medicinal Products for Human Use (CHMP), the Committee for Medicinal Products for Veterinary Use (CVMP), the Committee for Orphan Medicinal Products (COMP), the Committee on Herbal Medicinal Products (HMPC) and since July 2007 the Paediatric Committee (PDCO) for medicinal products for children (fig. 1). In the following, the structure and tasks of the CHMP which plays a pivotal role in the marketing procedures of medicinal products for human use is given as an example for the functions of the committees [20-22].

The CHMP is composed of currently 30 representatives (and alternates) of the competent authorities of each MS who are nominated for a 3-year period. Up to 5 coopted members (currently 4) can be part of the CHMP. They are elected among experts nominated by MS or the EMEA to gain additional expertise in a particular scientific area when necessary. The CHMP assesses MAA of medicinal products passing through the Centralised Procedure (described below) and is responsible for maintenance activities, such as the assessment of any modifications or extensions ('variations') to an existing MA. Furthermore, the CHMP functions as an ultimate arbitral authority in evaluation processes of a specific Mutual Recognition Procedure or a Decentralised Procedure (described below) when there is an unresolved disagreement between the MS on the grounds of 'potential serious risk to public health' and after the failure of earlier conciliatory proceedings with guidance by the Co-ordina- 


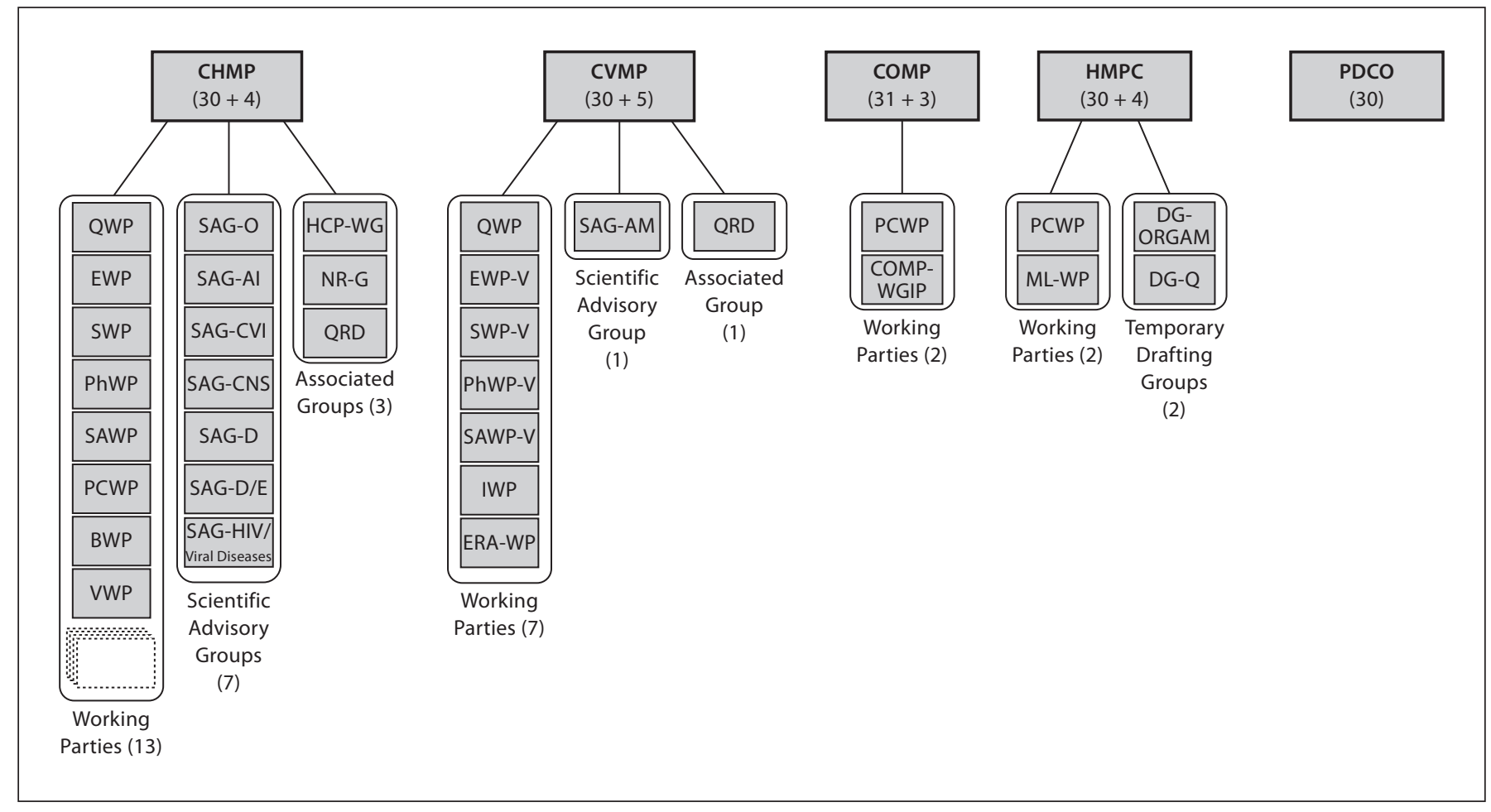

Fig. 1. The Boards of the European Medicines Agency (EMEA) involved in the evaluation and supervision of medicines for human and veterinary use. The numbers in parentheses indicate current number of members (+co-opted members) of the boards. QWP = Joint CHMP/CVMP Quality Working Party; SWP = Safety Working Party; PhWP = Pharmacovigilance Working Party; SAWP = Scientific Advice Working Party; PCWP = Patients' and Consumers' Working Party; VWP = Vaccine Working Party; SAG-O = Scientific Advisory Group on Oncology; SAG-AI = Scientific Advisory Group on Anti-Infectives; SAG-CVI = Scientific Advisory Group on Cardiovascular Issues; SAG-CNS = Scientific Advisory Group on Clinical Neuroscience; SAG-D = Scientific Advisory Group on Diagnostics; SAG-D/E = Scientific Advisory Group on Diabetes/Endocrinology; SAG-HIV/Viral Diseases =

tion Group for Mutual Recognition and Decentralised Procedures (Human) $\mathrm{CMD}(\mathrm{h})$ (see below) $[2,23]$.

The work of the CHMP is supported by currently 12 permanent and 1 temporary Working Parties (WP) such as the Biologics Working Party (BWP) or the Efficacy Working Party (EWP), each composed of members with special scientific and regulatory expertise in a certain field nominated by the CHMP members (fig. 1) $[13,24]$. The CHMP consults its WP on scientific issues relating to MAA and involves them in tasks such as drafting and revision of regulatory guidance documents [25]. Furthermore, the CHMP establishes several Scientific Advisory Groups (SAG) consisting of specialists on certain
Scientific Advisory Group on HIV/Viral Diseases; HCP-WG = Healthcare Professionals' Working Group; NR-G = (Invented) Name Review Group; QRD = Working Group on Quality Review of Documents; EWP-V = CVMP Efficacy Working Party; SWP-V = CVMP Safety Working Party; PhWP-V = CVMP Pharmacovigilance Working Party; SAWP-V = CVMP Scientific Advice Working Party; IWP = Immunologicals Working Party; ERA-WP = Environmental Risk Assessment Working Party; SAG-AM = Scientific Advisory Group on Antimicrobials; COMPWGIP = COMP Working Group with Interested Parties; ML$\mathrm{WP}=$ Working Party on Community Monographs and Community List; DG-ORGAM = Organisational Matters Drafting Group; DG-Q $=$ Quality Drafting Group.

issues nominated by the CHMP or the EMEA which provide advice to the CHMP in connection with the evaluation of specific types of medicinal products or treatments such as cardiovascular diseases (SAG on Cardiovascular Issues, SAG-CVI) or anti-infectives (SAG on Anti-Infectives, SAG-AI) [26, 27]. Additionally, three CHMP-associated groups with expertise in their respective areas support the CHMP in regulatory questions, the Healthcare Professionals Working Group (HCPWG), the (Invented) Name Review Group (NRG) and the Working Group on Quality Review of Documents (QRD) (fig. 1). Concerning allergen products neither a specific WP nor SAG exists and related guidance documents are 
established by the Biologics Working Party (BWP) or the Efficacy Working Party (EWP) and released by the CHMP.

\section{Heads of Medicines Agencies}

In the field of regulatory affairs of human or veterinary medicinal products, the heads of the competent authorities of the MS form a consortium called Heads of Medicines Agencies (HMA). The HMA displays a forum for the exchange of the views of the MS and communicates the views with the EMEA and the European Commission [17]. The HMA provides technical and scientific support in certain MA procedures (Mutual Recognition Procedure or Decentralised Procedure, described below) by two boards responsible for medicinal products for human or veterinary use: the Co-ordination Group for Mutual Recognition and Decentralised Procedures (Human), $\mathrm{CMD}(\mathrm{h})$ and the Co-ordination Group for Mutual Recognition and Decentralised Procedures (Veterinary), $\mathrm{CMD}(\mathrm{v})[5,6]$. Particularly in case of contradictory assessments of the MS concerning a particular MAA undergoing the Mutual Recognition Procedure or the Decentralised Procedure, the Co-ordination Groups $\mathrm{CMD}(\mathrm{h})$ or $\mathrm{CMD}(\mathrm{v})$ will provide guidance to resolve the issues [referral to $\mathrm{CMD}(\mathrm{h})$ or referral to $\mathrm{CMD}(\mathrm{v})$ ]. If the MS are not able to come to an agreement on an issue, the controversial case is referred to the CHMP or CVMP for arbitration ('referral for arbitration', Art. 32 of Directive 2001/83/EC or Art. 36 of Directive 2001/82/EC, respectively) $[2,4]$. Both boards, $\mathrm{CMD}(\mathrm{h})$ and $\mathrm{CMD}(\mathrm{v})$, are made up by a representative of the national authorities of each MS and their secretariats are provided by the EMEA.

Apart from resolving problems with individual applications for medicinal product applications, $\mathrm{CMD}(\mathrm{h})$ and $\mathrm{CMD}(\mathrm{v})$ release procedural guides, e.g. Best Practice Guides [28-31]. Currently, three WP of the HMA and one $\mathrm{CMD}(\mathrm{h})$ subgroup support the implementation of EU directives in the MS, fulfil harmonisation tasks or establish scientific guidance documents.

\section{Regulatory Procedures}

There are different regulatory procedures to obtain an MA for a medicinal product in Europe (fig. 2).

\section{National Procedure}

This procedure is only available for an application dossier submitted to one single MS according to the national drug law and the resulting MA is restricted to this country of choice.

Allergen Products and Regulatory Affairs
For entering the European market in two or more countries the following regulatory procedures exist.

Mutual Recognition Procedure (MRP) or

Decentralised Procedure (DCP) according to

Chapter 4 of Directive 2001/83/EC or Directive

2001/82/EC, respectively $[2,4,19,28,29]$

The MRP is applicable in case an existing MA in at least one single European MS shall be expanded to one or more additional states. The applicant submits identical dossiers to these countries and asks the MS which granted the MA to function as Reference Member State (RMS) to provide within 90 days an (if necessary updated) assessment report (AR) on the medicinal product to the MS, where an MA is sought and to coordinate the following procedure. The other Concerned Member States (CMS) should recognise the AR of the RMS and the application dossier and approve the MA within 90 days. If an MS decides to reject the application which is possible exclusively in case of a serious public health concern, a referral according to Art. 32 or Art. 36, respectively, becomes necessary (see above).

The DCP is similar to the MRP and is applied for a medicinal product to be marketed in parallel in two or more MS if no MA within Europe exists. The manufacturer provides an identical application dossier to all MS of choice and chooses one of them to be RMS which prepares the AR within 120 days as basis for the decision of the remaining CMS.

Every MRP or DCP is performed with the assistance of the Co-ordination Groups for Mutual Recognition and Decentralised Procedures(Human/Veterinary) CMD(h)/ $\mathrm{CMD}(\mathrm{v})$ of the HMA.

From the formal point of view, MRP and DCP are European regulatory procedures applied in at least two countries of choice, but the final MAs are granted as national MA by the respective national competent authorities. MAs of a medicinal product in several MS (approved by a successful MRP or DCP) can be expanded to further European MS. In that case, another MRP, a so-called 'repeat use (of the MRP)' informally also called 'second wave', has to be started with the intended country/countries of choice as CMS and a country with an existing MA functioning as RMS. In general, it is possible to market a medicinal product in an increasing number of European countries by consecutive repeat use of MRPs. A potential pitfall may lie in a refusal of the MA in a subsequent repeat use procedure as this compulsively causes withdrawals or revocations of previously granted MAs in all the MS.

Arch Allergy Immunol 2008;147:263-275 

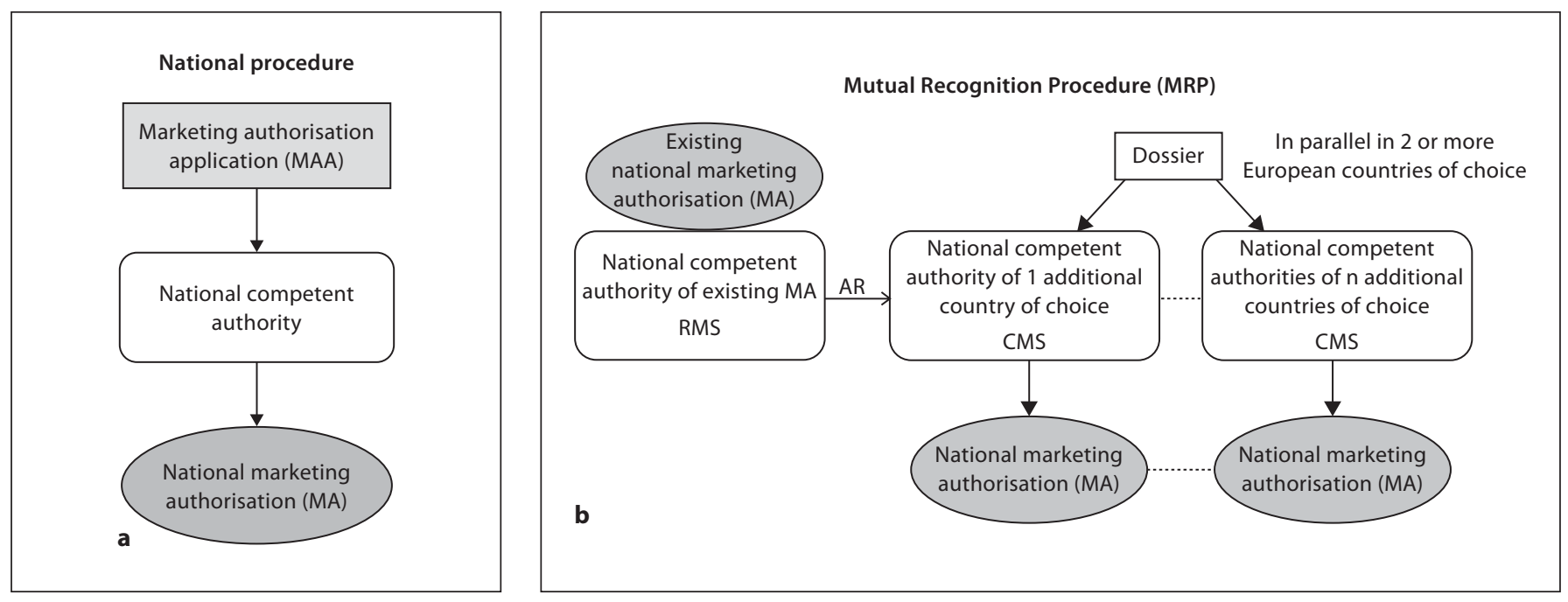

Fig. 2. The four different regulatory procedures to apply for a marketing authorisation in Europe. A successful marketing authorisation application (MAA) in one European member state results in a marketing authorisation (MA) valid in exclusively one member state. A national MA can be expanded to one or more additional member states via the MRP. When applying for an MA in two or more member states for the first time, the DCP has to be applied. Consequently, MRP and DCP are similar regulatory procedures. Both procedures result in an MA for a medicinal product in two or more member states. An MA granted by the CP is valid in all European member states after one single regulatory procedure. $\mathrm{AR}=$ Assessment report; $\mathrm{RMS}=$ Reference Member State; CMS = Concerned Member State; CHMP = Committee for Medicinal Products for Human Use. National Procedure (a), Mutual Recognition Procedure (MRP) (b), Decentralised Procedure (DCP) (c), and Centralised Procedure (CP) (d) are shown.
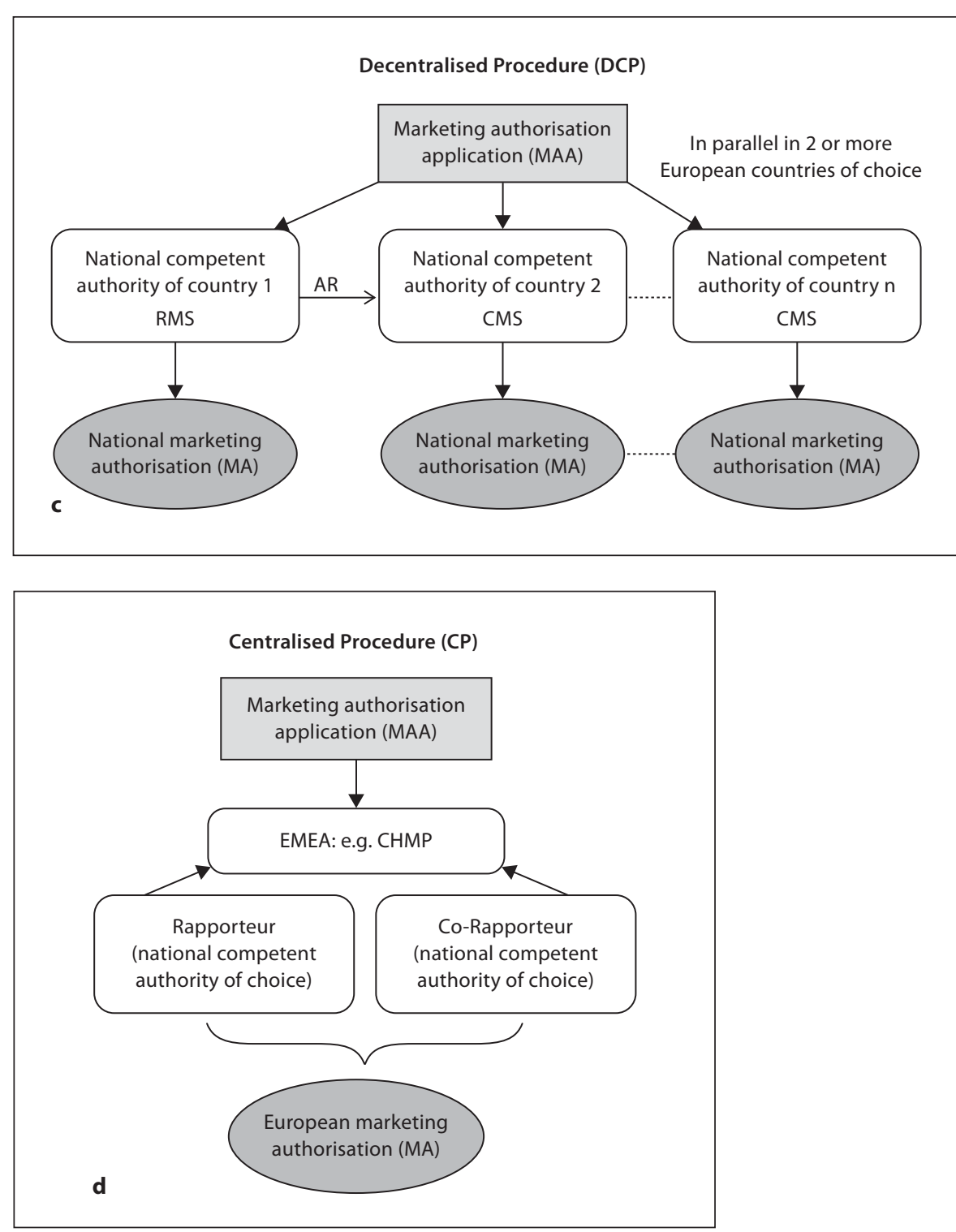
Centralised Procedure (CP) according to Regulation

(EC) $726 / 2004[9,19]$

An application dossier is submitted to the EMEA which coordinates the evaluation process. Two MS are selected as Rapporteur and Co-Rapporteur and assess the application dossier as representatives for all MS and provide their assessment result as a proposal to the CHMP. The CHMP with support of its WP (if needed) elaborates an opinion within 210 days, which is the basis for the decision of the Commission about granting the MA. The formal MA is not granted by the EMEA but by the European Commission or the European Council. An MA granted through the $\mathrm{CP}$ has validity in the entire Community and the associated states.

The CP is mandatory for medicinal products fulfilling one of the following criteria: developed by biotechnological processes, containing a new active substance, being innovative or orphan, or intended as drug for the indications of AIDS, cancer, neurodegenerative disorders and diabetes (list of indications will be extended in May 2008 by autoimmune diseases, immune dysfunctions and viral diseases) (Art. 3, para. 2 and Annex of Regulation (EC) $726 / 2004$ [9]). For medicinal products that do not fall under any of the above-mentioned categories an MAA can be submitted to the EMEA to undergo the $\mathrm{CP}$, providing that the medicinal product constitutes a significant therapeutic, scientific or technical innovation or that the product is in any other respect in the interest of patient or animal health. In fact, the purpose of the $\mathrm{CP}$ is to make innovative medicinal products immediately available in the whole EC. Up to date, all therapeutic and many of the diagnostic allergen products in Europe are extracts of natural source materials such as pollen or mites which comprise long-established active substances and therefore undergo the MRP or DCP. Novel biotechnological allergen products such as recombinant allergens will be subjected to the CP (see below).

\section{Common Technical Document Format}

Regardless of the procedure, the application dossier should be organised according to the Common Technical Document (CTD) format in five modules. The CTD format is international and besides module 1 which contains administrative information the modules $2-5$ of the dossier can be used for applications in Europe, the USA or Japan. Further specific advice concerning regulatory procedures and presentation of the dossier are provided in the Notice to Applicants which is the Volume 2 of the EudraLex collection [32].

Allergen Products and Regulatory Affairs
Although there are several European procedures to apply for an MA, the scientific and technical requirements for a medicinal product to be marketed are identical and independent of the applied regulatory procedure. The regulatory procedure to be applied can strongly be influenced by the kind of medicinal product to be marketed. This is the case for recombinant allergens which have to be submitted by the CP because they are biotechnologically produced medicinal products. In case that the regulatory procedure is not determined by the kind of the medicinal products, strategic considerations of the applicant will lead to the decision for a suitable regulatory procedure. Factors such as the intended number of the countries with valid MA as well as time and cost of a regulatory procedure and many more will influence the strategic considerations of a manufacturer.

\section{Regulatory Procedures and Guidance Documents Applying to Allergen Products}

\section{Regulatory Documents with Particular Impact on Allergen Products}

According to Art. 1 para. 4 (b) of Directive 2001/83/ EC an allergen product means 'any medicinal product which is intended to identify or induce a specific acquired alteration in the immunological response to an allergizing agent' [2]. Not only allergen products for therapeutic use but also allergen products for diagnostic use are considered as medicinal products and consequently require an MA. In addition, this directive characterises medicinal products as substances which are 'administered to human beings' (Art. 1 para. 2 sentence 2). Allergen products for in vivo tests such as skin tests or provocation tests are administered to human beings by the skin route or the oral/mucosal route. Therefore, allergen products made for skin testing as well as those for provocation tests have the status of medicinal products and consequently have to undergo a licensing procedure for medicinal products. In contrast, serological allergy tests do not come in contact with a human being and therefore are not defined as medicinal products. Serological allergy tests represent so-called 'in vitro diagnostic medical devices (IVDs)' and do not need an MA. The marketing of in vitro medical devices is regulated by the Directive on in vitro Diagnostic Medical Devices. If the devices follow requirements laid down in this directive, they get a Communauté Européenne (CE) marking of conformity. Conformity assessment procedures differ from those of MAA evaluation [33].

Arch Allergy Immunol 2008;147:263-275 
Besides general instructions applied to regulatory affairs of allergen products there are two guidance documents which are specific for allergen products, the Monograph on Allergen Products of the European Pharmacopoeia [34] and the Note for Guidance on Allergen Products released by the Committee for Proprietary Medicinal Products (CPMP) (former name of the CHMP) and the Biotechnology Working Party (BWP) [former name of the Biologics Working Party (BWP)] [11]. The scopes and topics of the Note for Guidance and the Monograph are more or less identical.

The Monograph on Allergen Products solely deals with allergen products derived from 'naturally occurring source materials' such as pollen, mites or epithelia of animals which are intended for immunotherapy or in vivo diagnostic use [34]. The Monograph describes the requirements for source materials, for the production processes and the control steps during the production to show identity, purity and stability and it provides several specification limits. Batch-to-batch consistency has to be demonstrated by comparison with an In-House Reference Preparation (IHRP) which has to be characterised by protein content, quantitative and qualitative allergen content and biological potency, for example, by skin tests. The Monograph proposes several test procedures to demonstrate the required criteria but does not indicate specific laboratory methods to comply with.

Like the Monograph, the Note for Guidance on Allergen Products requires the detailed description of the source materials and the excipients, the production processes and control steps of intermediate and finished products. In-House Reference Preparations (IHRP) have to be characterised concerning allergenic activity, protein composition and the presence of all relevant allergens to demonstrate batch-to-batch consistency. Several methods showing the required criteria are listed in the Note for Guidance. Both, the Note for Guidance and the Monograph limit the total allergenic activity which is an estimate for the potency of a finished product to not less than $50 \%$ and not more than $200 \%$ of the indicated potency. In addition, the Monograph leaves it to the applicant to apply other justified validated potency tests such as the determination of the content of individual allergens postulating that the content of a single allergen should account for $50-200 \%$ of the stated amount. According to the Note for Guidance, at the end of shelf life not less than $30 \%$ of the stated allergenic activity should be maintained. Nowadays, these rather wide specification ranges do not reflect state-of-the-art of science and therefore may be narrowed in the future.
The only requirements referring safety and efficacy are listed in the Note for Guidance indicating that the 'concept of taxonomic family' can be applied for safety testing and extrapolation of clinical data. According to this concept, toxicological and clinical data obtained with one member of a taxonomic family may be extrapolated to other members of the same family provided identical manufacturing procedures are applied. This concept can only be operated to allergen products from sources of the same taxonomic family and is excluded for mixtures of members of different taxonomic families.

The Note for Guidance as well as the Monograph exclusively deals with quality issues with the exception of the 'taxonomic family concept' of the Note for Guidance which can be applied to clinical studies but which is not substantial in the field of clinical studies. Currently, two guidelines provide requirements concerning efficacy and safety in connection with allergic diseases: The 'Guideline on the Clinical Development of Medicinal Products for the Treatment of Allergic Rhino-Conjunctivitis' [35] is about clinical studies of preventive and therapeutic drugs against allergic rhinoconjunctivitis but excludes products for specific immunotherapy (SIT) and anti-IgE agents. The 'Note for Guidance on the Clinical Investigation of Medicinal Products in the Treatment of Asthma' does not primarily cover allergen products since according to this guideline asthma is not necessarily linked with atopy and increased IgE level [36]. As a consequence, guidance documents with special emphasis on clinical studies with allergen products and detailed information on performing SIT are still lacking in Europe.

Currently, three undertakings aim to provide allergen product-specific instructions as an adaptation to the state-of-the-art in allergy research and to the needs shown in regulatory practice. First, the Note for Guidance on Allergen Products of 1996 is under fundamental revision concerning production and quality issues [25]. Among other objectives the 'principle of taxonomic family' shall be transformed to the 'principle of homologous groups' (see article by Lorenz et al. [37]). Additionally, the revised guideline is planned to encompass biotechnologically derived allergen products such as recombinant allergens and derivatives thereof. A draft of the revised Note for Guidance has been prepared by a group of European experts from competent authorities. The revised Note for Guidance will be denominated Guideline and will focus on production and quality issues [38]. After approval of the Biologics Working Party (BWP) and after adoption by the CHMP the draft was published on 20th September 2007 on the website of the EMEA for public consultation 
[38]. Over a period of six months the public is invited to send comments on the draft to the EMEA. All comments will be taken into consideration and discussed in detail by the drafting group, and a point-by-point evaluation will be prepared. Ultimately, the final version of the revised Guideline has to pass the BWP and subsequently has to be adopted and released by the CHMP, presumably in the second half of 2008.

Second, the Monograph on Allergen Products of the European Pharmacopoeia will likewise be adapted concerning standardisation issues and acceptance criteria.

Third, the Efficacy Working Party (EWP) at the EMEA is preparing a guideline on clinical studies with medicinal products for SIT in the preventive and curative treatment of allergic diseases [39]. This guideline will provide guidance on clinical trials with allergen products which contain natural or recombinant allergens. The future guideline will give detailed information on study design aspects such as inclusion/exclusion criteria, endpoints, study duration, dose regimen, dose response studies, comparison of data resulting from different routes of application, pharmacodynamic and pharmacokinetic studies as well as clinical trials in children. The EWP agreed to a draft version of the guideline and submitted the document to the CHMP. In May 2007 the CHMP adopted the draft of the guideline and it was published on the website of the EMEA for consultation [40]. The EWP is a board of European experts from the national regulatory authorities in the field of clinical trials, composed of one expert per MS and additional experts, nominated from an expert list from the CHMP [41]. The currently 33 members of the EWP have high expertise in the field of clinical trials but not necessarily in allergen products or in regard to the particularities of SIT. At a first view this special situation could be suspected to cause problems, but it ensures a highly objective evaluation of different treatment strategies. Moreover, the EWP usually involves external clinical experts in cases where it feels that the number of expert members of the EWP is not high enough to comprehensively deal with problems of a particular field.

\section{Allergen Products Approved by European Regulatory Procedures}

To date, only a few allergen products have passed a successful European regulatory procedure. These allergen products have undergone the MRP and possess an MA granted by competent national authorities. For example, Nixema ${ }^{\circledR}$ is a medicated plaster for cutaneous use with two test substance patches intended for the diagnosis of contact dermatitis towards nickel and fragrance mix. Second, Grazax ${ }^{\circledR}$ is an oral lyophilisate containing a standardised allergen extract of grass pollen from the grass species Phleum pratense indicated for the treatment of grass pollen-induced rhinitis and conjunctivitis in adult patients with clinically relevant symptoms and diagnosed with a positive skin prick test and/or with specific IgE test to grass pollen. Grazax ${ }^{\circledR}$ obtained the MA in Germany in October 2006. The third example is Alu$\operatorname{tard} A v a n z^{\circledR}$, a suspension for injection containing standardised allergen extract of Phleum pratense indicated to treat grass pollen-induced rhinitis and conjunctivitis in adults with a positive skin prick test and/or with IgE antibodies specific to grass pollen. Alutard Avan $z^{\circledR}$ has the MA in Germany since December 2006.

\section{Named Patient Products}

In 1989, at a rather late time, the allergen products became subject of the European pharmaceutical legislation with Directive 89/342/EEC defining allergen products [42]. However, allergen products can be produced for an individual patient due to an individual medical prescription. These so-called 'named patient products' in general do not need an MA in European countries. Additionally, the Note for Guidance on Allergen Products as well as the Monograph on Allergen Products both do not apply to named patient products. Consequently, named patient products do not have to fulfil the quality criteria of allergen products which possess an MA. In some European countries named patient products represent a large portion of therapeutic allergen products meaning that a considerable percentage of patients obtain an SIT with allergen products that (1) do not have quality proven and independently evaluated according to the criteria of the Monograph on Allergen Products and the Note for Guidance on Allergen Products and (2) do not have an MA granted by national competent authorities. In practice named patient products are industrially produced and provided to medical practitioners according to an individual prescription. However, the scope of Directive 2001/83/EC concerns 'medicinal products either prepared industrially or manufactured by a method involving an industrial process' (Art. 2) [2] and because directives have to be implemented in the national legislation of each MS each national drug law focuses on industrially produced medicinal products. The draft of the revised Guideline on Allergen Products aims to include allergen products that have been 'manufactured by a method involving an industrial process as defined by Directive 2001/83/EC'. This phrase would include named patient products [38]. It would make sound sense to us to subject 


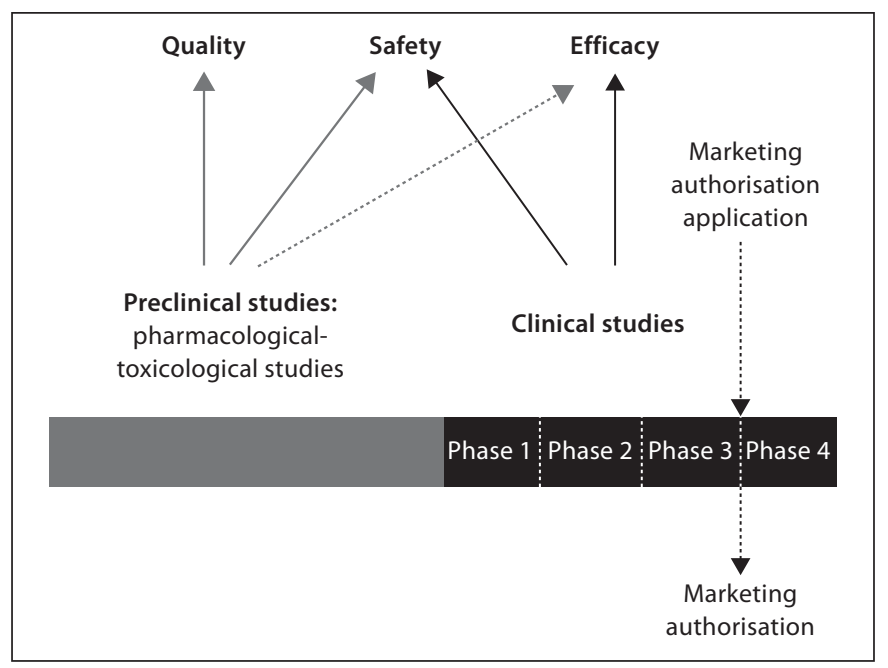

Fig. 3. Regulatory development of a medicinal product for human use up to marketing authorisation. The preclinical studies comprise studies on pharmacology and toxicology of the medicinal product to gain information on its quality and safety and, to a limited extent, on its efficacy. In case of satisfactory results of the preclinical studies, the medicinal product enters the clinical studies performed on human beings to assess the safety and efficacy of the medicinal product. The clinical studies include four consecutive phases starting with a sample of healthy volunteers (Phase 1), followed by a limited sample of patients affected with the illness of subject (Phase 2) and completed with a large number of affected subjects (Phase 3). Postmarketing surveillance studies (Phase 4) analyse the medicinal product in clinical practice after being marketed.

all allergen products which are manufactured industrially, including named patient products, to the quality criteria of the Guideline on Allergen Products and the Monograph on Allergen Products.

\section{Novel Allergen Products Derived from Recombinant DNA Technology}

During the last decade more than 250 allergens have been produced by recombinant DNA technology in diverse expression systems and have been applied in component-resolved diagnosis as well as in clinical trials [4347]. Therefore, recombinant allergens are an example of potential novel allergen products for SIT [48]. Since the $\mathrm{CP}$ is mandatory for 'medicinal products developed by means of ... recombinant DNA technology' (Annex of Regulation 726/2004), medicinal products containing recombinant allergens as active substance have to undergo the $\mathrm{CP}$ and the regulatory procedure cannot be chosen according to strategic considerations by the manufacturer (see above) $[9,19]$. Moreover, as medicinal products based on recombinant allergens need an MA by the CP, they cannot be marketed without a licensing procedure as named patient products.

Currently, the legal framework does not provide instructions specific for allergen products derived from recombinant DNA technology. The Monograph on Allergen Products of the European Pharmacopoeia explicitly excludes allergen products manufactured by recombinant DNA technology and the Note for Guidance on Allergen Products hardly can be applied to allergen products containing recombinant allergens as substance.

To date, seven guidance documents addressing the field of recombinant DNA technology can be considered in the regulatory affairs of recombinant allergens as allergen products [10, 12, 49-53]. These Notes for Guidance from the 1990s primarily cover quality issues such as the analysis of the expression construct used in cell lines for the production of the recombinant protein [12] or the characterisation of the expressing cell types $[10,50]$. The guidelines also specify test procedures and acceptance criteria for medicinal products consisting of recombinant peptides as well as stability requirements and quality conditions for controlling the entire production process $[10,49,51]$. One guidance document refers to the preclinical safety evaluation of biotechnologically derived pharmaceuticals in animal models [53].

However, the current undertakings aim to adapt the allergen product-specific guidance documents to recombinant allergens. The new guideline for clinical studies with allergen products for SIT will include clinical evaluation of recombinant allergens [40]. Likewise, the revised version of the Note for Guidance on Allergen Products, the future Guideline on Allergen Products: Production and Quality Issues will give instructions to control the quality of recombinant allergens. Since hypoallergenic derivatives of recombinant allergens with reduced IgEbinding capacity may be candidates for an improved SIT, the revised Guideline on Allergen Products will propose test procedures for potency tests of hypoallergenic molecules made by DNA technology [38].

Some problems concerning the regulatory procedures of recombinant allergens and derivates thereof as medicinal products remain unresolved. For example, strategies for SIT with patient-tailored mixtures of recombinant allergens dependent on the individual sensitisation pattern of a patient have to be evolved. According to the current legal situation each individual mixture would represent a new medicinal product and therefore would require an individual MA. Furthermore, the number of allergic subjects with a certain sensitisation pattern to individual allergen 
molecules could be so small that adequately powered clinical trials may be very difficult to perform. Currently, the product-specific guidance documents are not fully appropriate for novel allergen products such as patient-tailored mixtures of recombinant allergens for SIT. Other medicinal products with an analogous therapeutic principle which could serve as a model for the licensing procedure are lacking. Before applying for an MA for patient-tailored mixtures of recombinant allergens a manufacturer would be well advised to ask EMEA for scientific regulatory advice at an early stage of development of the allergen product to adjust the studies to the requirements.

\section{Clinical Trials}

Figure 3 illustrates the general development of a medicinal product starting with the preclinical studies which provide information on the quality by pharmacological studies and on the safety profile by toxicological studies. The toxicological studies are mostly performed in animal models (for example, mice, rats, dogs) and comprise tests on mutagenic and carcinogenic effects and on the influence on the reproductive system. For biologicals such as allergen products, tests for mutagenicity and carcinogenicity are not always demanding. When the results of preclinical studies are promising the medicinal product will enter the clinical studies which are performed on healthy and diseased subjects. The clinical trials have to be approved by the national competent authority in the country where the clinical trials will be conducted. To apply for a clinical trial authorisation (CTA) the manufacturer submits the so-called Investigational Medicinal Product Dossier (IMPD) with data of the preclinical studies as well as the intended study protocol that describes the objective(s), design, methodology, statistical considerations and organisation of a trial. The conditions for preclinical and clinical studies are laid down in general as well as in medicinal product-specific guidance documents and have to be performed according to the principles of good manufacturing practice (GMP) and 'Good Clinical Practice' (GCP) [53-57]. The national competent authority assesses the data and decides on the CTA. Additionally, the responsible ethics committee has to approve the study protocol and the investigator's qualification.

The clinical studies comprise four consecutive phases: Phase 1 trials are conducted with a limited number of healthy volunteers to gain pharmacokinetic and pharmacodynamic data and to test the safety profile of a medicinal product. In phase 2 performed with a sample of patients affected by the disease first results on the efficacy of a medicinal product are obtained. In case of satisfac- tory results from the phases 1 and 2, efficacy and safety of the medicinal product will be evaluated in phase 3 with a large sample of affected patients. Finally, after phase 3, an MAA can be submitted. In case of a granted MA the medicinal product can be marketed in the country/countries with valid MA. After marketing, the postmarketing surveillance studies monitor safety and efficacy of a medicinal product in medical practice; they comprise the so-called phase 4 studies.

The authorisation of a clinical trial (CTA) should not be mixed up with the MA; the CTA is the prerequisite to perform clinical studies and the results of the clinical studies have to be enclosed in the MAA dossier together with the preclinical studies.

Concerning allergen products, in many cases the competent authorities do not demand phase 1 studies because most side effects of an allergen product are associated with allergic reactions and consequently cannot be studied in healthy subjects. Additionally, allergen products involve the risk of sensitising healthy volunteers to allergens. However, it cannot be generalised that for allergen products the phase 1 study can be omitted. The requirements for clinical studies depend on the specific allergen product and are influenced by various factors such as active substance, formulation or type of adjuvant. Additionally, the inclusion/exclusion criteria of the study population and the therapeutic concept may have an impact on the design of the study protocol. One possibly observed outcome, when applying an allergen product for an SIT in allergic subjects (among other clinical endpoints) is the reduction of allergic symptoms. A different study protocol and different clinical endpoints would probably be chosen for a prophylactic application of allergen products. This could be the case with a prophylactic SIT for still healthy children of atopic parents who have a high risk of becoming allergic too. The absence of allergic symptoms could serve as primary endpoint of such a study, while the main safety issue to be addressed would be the possibility to induce allergic sensitisation in response to the prophylactic treatment. Since the study population would comprise not only children, but, moreover, healthy children ethical conditions also strongly influence the decision on a CTA.

\section{Concluding Remarks}

Since its beginning in 1965 the European pharmaceutical legislation has evolved during the past decades into a complex framework and is in a continuous process of 
development to cover additional fields and novel challenges. Several strategies towards obtaining an MA can be applied.

Relatively late in 1989, allergen products were included in the scope of European pharmaceutical legislation. Several guidance documents address specific aspects of allergen products such as the Note for Guidance on Allergen Products and the Monograph on Allergen Products of the European Pharmacopoeia.

All regulatory documents need continuous amendment to be adapted to state-of-the-art in medical research and to requirements resulting from regulatory practice. Particularly, the products containing allergens derived from recombinant DNA technology present a challenge: although production and acceptance criteria for recombinant proteins are well regulated, the field of clinical allergy has several specific aspects, the main problem being that the allergic immune response to proteins from the same source material can be highly diverse. Moreover, as the exact mechanism of SIT is still not fully elucidated, designing a potency test related to the mechanism of action and the intended clinical effect of allergen products remains problematic. Currently, several undertakings aim to update the allergen product-specific regulatory documents and create new ones suitable for novel products.

\section{References}

1 Consolidated versions of the Treaty on European Union and of the Treaty establishing the European Community. OJ 2006;C321E: $1-331$.

2 Directive 2001/83/EC of the European Parliament and of the Council on the Community code relating to medicinal products for human use. OJ 2004;L311:67-122.

3 Council Directive 65/65/EEC of 26 January 1965 on the approximation of provisions laid down by Law, Regulation or Administrative Action relating to proprietary medicinal products. OJ 1965;22:369-373.

4 Directive 2001/82/EC of the European Parliament and of the Council of 6 November 2001 on the Community code relating to veterinary medicinal products. OJ 2001;L311: $1-66$.

5 Directive 2004/27/EC of the European Parliament and the Council of 31 March 2004 amending Directive 2001/83/EC on the Community code relating to medicinal products for human use. OJ 2004;L136:34-57.

6 Directive 2004/28/EC of the European Parliament and of the Council of 31 March 2004 amending Directive 2001/82/EC on the Community code relating to veterinary medicinal products. OJ 2007;L136:58-84.

7 Commission Directive 2003/63/EC of 25 June 2003 amending Directive 2001/83/EC of the European Parliament and of the Council on the Community code relating to medicinal products for human use. OJ 2003; L159:46-94.

8 EudraLex: The rules governing medicinal products in the European Union. http://ec. europa.eu/enterprise/pharmaceuticals/eudralex/index.htm.

9 Regulation (EC) No. 726/2004 of the European Parliament and of the Council of 31 March 2004 laying down Community procedures for the authorisation and supervision of medicinal products for human and veterinary use and establishing a European Medicines Agency. OJ 2004;L136:1-33.
10 Guideline: Production and quality control of medicinal products derived by recombinant DNA technology. 1994;3AB1a.

11 Committee for Proprietary Medicinal Products (CPMP) and Biotechnology Working Party (BWP): Note for Guidance on Allergen Products. 1996;CPMP/BWP/243/96.

12 Committee for Proprietary Medicinal Products (CPMP) and International Conference on Harmonisation of Technical Requirements for Registration of Pharmaceuticals for Human Use (ICH): ICH Topic Q5B/Note for Guidance on quality of biotechnological products: analysis of the expression construct in cell lines used for production of $r$ DNA derived protein products. 2005;CPMP/ $\mathrm{ICH} / 139 / 95$.

13 Committee for Proprietary Medicinal Products (CPMP): Points to consider on the reduction, elimination or substitution of Thiomersal in vaccines. 2001;CPMP/BWP/2517/00.

14 Bundesministerium für Gesundheit: Allgemeine Verwaltungsvorschrift zur Durchführung des Arzneimittelgesetzes (AMGVwV). BAnz 2006;63:2287-2289.

15 Bundesinstitut für Arzneimittel und Medizinprodukte (BfArM), Paul-Ehrlich-Institut: 3. Bekanntmachung zur klinischen Prüfung von Arzneimitteln am Menschen - Gemeinsame Bekanntmachung des Bundesinstitutes für Arzneimittel und Medizinprodukte und des Paul-Ehrlich-Instituts vom 10. August 2006. BAnz 2006;166:6072.

16 European Directorate for the Quality of Medicines (EDQM): II. Introduction; in Council of Europe (ed): European Pharmacopoeia. Strasbourg, ed 6, 2008, pp v-vii.

17 Heads of Medicines Agencies (HMA). http:// www.hma.eu/.

18 European Medicines Agency (EMEA). http://www.emea.europa.eu/.

19 Seitz R: EU procedures for marketing authorization of pharmaceutical products. Arb Paul Ehrlich Inst Bundesamt Sera Impfstoffe Frankf A M 2006;95:60-63.
20 Regulation (EC) No 1901/2006 of the European Parliament and of the Council of 12 December 2006 on medicinal products for paediatric use and amending Regulation (EEC) No. 1768/92, Directive 2001/20/EC and Regulation (EC) No. 726/2004. OJ 2006;L378:1-19.

21 Regulation (EC) No. 1902/2006 of the European Parliament and of the Council of 20 December 2006 amending Regulation $1901 / 2006$ on medicinal products for paediatric use. OJ 2006;L378/20:1-2.

22 Committee for Medicinal Products for $\mathrm{Hu}$ man Use (CHMP): Committee for Medicinal Products for Human Use - Rules of Procedure. 2004;EMEA/CHMP/111481/2004.

23 Guideline on the definition of a potential serious risk to public health in the context of Article 29(1) and (2) of Directive 2001/83/ EC - March 2006 (2006/C 133/05). OJ 2006; C133:5-7.

24 European Medicines Agency (EMEA), Committee for Medicinal Products for Human Use (CHMP), and Biologics Working Party (BWP): Mandates, objectives and rules of procedure for the CHMP Biologics Working Party (BWP). 2005;EMEA/CHMP/BWP/ 206296/2004.

25 Committee for Medicinal Products for $\mathrm{Hu}$ man Use (CHMP) and Biologics Working Party (BWP): Concept Paper on the revision of the Note for Guidance on Allergen Products (CPMP/BWP/243/96): production and quality issues. 2005;Doc.Ref.:CHMP/BWP/ 229472/2005.

26 European Medicines Agency (EMEA) and Committee for Medicinal Products for $\mathrm{Hu}$ man Use (CHMP): Mandate, objectives and rules of procedure for the CHMP Scientific Advisory Group on Cardiovascular Issues (SAG-CVS). 2007;EMEA/CHMP/337299/ 2005

27 European Medicines Agency (EMEA) and Committee for Medicinal Products for $\mathrm{Hu}-$ man Use (CHMP): Mandate, objectives and rules of procedure for the CHMP Scientific 
Advisory Group on Anti-Infectives (SAGAI). 2004;EMEA/CHMP/159394/2004.

28 Co-ordination Group for Mutual Recognition and Decentralised Procedures - Human $[\mathrm{CMD}(\mathrm{h})]$ : Best Practice Guide for MRP. http://heads.medagencies.org/index.html.

29 Co-ordination Group for Mutual Recognition and Decentralised Procedures - Human $[\mathrm{CMD}(\mathrm{h})]$ : Best Practice Guide for the Reference Member State in the Mutual Recognition and Decentralised Procedures. http:// heads.medagencies.org/index.html.

30 Co-ordination Group for Mutual Recognition and Decentralised Procedures - Human [CMD(h)]: Decentralised Procedure: Member States' Standard Operation Procedure. http://heads.medagencies.org/index.html.

31 European Medicines Agency (EMEA) and Co-ordination Group for Mutual Recognition and Decentralised Procedures - Veterinary $[\mathrm{CMD}(\mathrm{v})]$ : Best Practice Guide for Veterinary Decentralised Procedure (DCP), ed 01. 2007;EMEA/CMD(v)/63793/2006.

32 EudraLex Volume 2: Notice to Applicants. http://ec.europa.eu/enterprise/pharmaceuticals/eudralex/homev2.htm\#2a.

33 Directive 98/79/EC of the European Parliament and of the Council of 27 October 1998 on in vitro diagnostic medical devices. OJ 1998;L331:1-37.

34 European Directorate for the Quality of Medicines (EDQM): Monograph: Allergen Products - Producta allergenica; in Council of Europe (ed): European Pharmacopoeia. Strasbourg, ed 6, 2008, pp 679-680.

35 Committee for Medicinal Products for $\mathrm{Hu}$ man Use (CHMP) and Efficacy Working Party (EWP): Guideline on the clinical development of medicinal products for the treatment of allergic rhino-conjunctivitis. 2004;CHMP/EWP/2455/02.

36 Committee for Proprietary Medicinal Products (CPMP) and Efficacy Working Party (EWP): Note for Guidance on the clinical investigation of medicinal products in the treatment of asthma. 2002;CPMP/EWP/ 2922/01.

37 Lorenz AR, Lüttkopf D, May S, Scheurer S, Vieths S: The principle of homologous groups in regulatory affairs of allergen products - a proposal. Int Arch Allergy Immunol 2009; in press.

38 European Medicines Agency (EMEA), Committee for Medicinal Products for Human Use (CHMP), and Biologics Working Party (BWP): Draft: Guideline on allergen products: production and quality issues. 2007; EMEA/CHMP/BWP/304831/2007.

39 Committee for Medicinal Products for $\mathrm{Hu}-$ man Use (CHMP) and Efficacy Working Party (EWP): Concept Paper on the preparation of a guideline on the clinical development of products for specific immunotherapy for the treatment of allergic diseases. 2006;EMEA/CHMP/EWP/18504/2006.
40 Committee for Medicinal Products for $\mathrm{Hu}$ man Use (CHMP): Draft: Guideline on the clinical development of products for specific immunotherapy for the treatment of allergic diseases. 2007;Doc.Ref.CHMP/EWP/18504/ 2006.

41 European Medicines Agency (EMEA), Committee for Medicinal Products for Human Use (CHMP), and Efficacy Working Party (EWP): Mandate, objectives and rules of procedure for the CHMP Efficacy Working Party. 2004;EMEA/CHMP/EWP/139722/ 2004.

42 Council Directive 89/342/EEC of 3 May 1989 extending the scope of Directives 65/65/EEC and 75/319/EEC and laying down additional provisions for immunological medicinal products consisting of vaccines, toxins or serums and allergens. OJ 1989;L142:14-15.

43 Lidholm J, Ballmer-Weber BK, Mari A, Vieths S: Component-resolved diagnostics in food allergy. Curr Opin Allergy Clin Immunol 2006;6:234-240.

44 Heiss S, Mahler V, Steiner R, Spitzauer S, Schweiger C, Kraft D, Valenta R: Component-resolved diagnosis (CRD) of type I allergy with recombinant grass and tree pollen allergens by skin testing. J Invest Dermatol 1999;113:830-837.

45 van Hage-Hamsten M, Pauli G: Provocation testing with recombinant allergens. Methods 2004;32:281-291.

46 Jutel M, Jaeger L, Suck R, Meyer H, Fiebig H, Cromwell O: Allergen-specific immunotherapy with recombinant grass pollen allergens. J Allergy Clin Immunol 2005; 116:608613.

47 Niederberger V, Horak F, Vrtala S, Spitzauer S, Krauth MT, Valent P, Reisinger J, Pelzmann M, Hayek B, Kronqvist M, Gafvelin G, Gronlund H, Purohit A, Suck R, Fiebig H, Cromwell O, Pauli G, van Hage-Hamsten M, Valenta R: Vaccination with genetically engineered allergens prevents progression of allergic disease. Proc Natl Acad Sci USA 2004;101(suppl 2):14677-14682.

48 Valenta R, Niederberger V: Recombinant allergens for immunotherapy. J Allergy Clin Immunol 2007;119:826-830.

49 Committee for Proprietary Medicinal Products (CPMP) and International Conference on Harmonisation of Technical Requirements for Registration of Pharmaceuticals for Human Use (ICH): ICH Topic S6C/Note for Guidance on quality of biotechnological products: stability testing of biotechnological/biological products. 1995;CPMP/ICH/ 138/95.
50 Committee for Proprietary Medicinal Products (CPMP) and International Conference on Harmonisation of Technical Requirements for Registration of Pharmaceuticals for Human Use (ICH): ICH Topic Q5D/Note for Guidance on quality of biotechnological products: derivation and characterisation of cell substrates used for production of biotechnological/biological products. 1997; CPMP/ICH/294/95.

51 Committee for Proprietary Medicinal Products (CPMP) and International Conference on Harmonisation of Technical Requirements for Registration of Pharmaceuticals for Human Use (ICH): ICH Topic Q6B/Note for Guidance on specifications: test procedures and acceptance criteria for biotechnological/biological products. 1999;CPMP/ ICH/365/96.

52 Committee for Proprietary Medicinal Products (CPMP) and Biotechnology Working Party (BWP): Guideline on comparability of medicinal products containing biotechnology-derived proteins as active substance: quality issues. 2003;EMEA/CPMP/BWP/ 3207/00/Rev1.

53 Committee for Proprietary Medicinal Products (CPMP) and International Conference on Harmonisation of Technical Requirements for Registration of Pharmaceuticals for Human Use (ICH): ICH Topic S6/Note for Guidance on preclinical safety evaluation of biotechnology-derived pharmaceuticals. 1998;CPMP/ICH/302/95.

54 Committee for Proprietary Medicinal Products (CPMP) and International Conference on Harmonisation of Technical Requirements for Registration of Pharmaceuticals for Human Use (ICH): ICH Topic S2A/Note for Guidance on genotoxicity: Guidance on specific aspects of regulatory genotoxicity tests for pharmaceuticals. 1995;CPMP/ $\mathrm{ICH} / 141 / 95$.

55 Committee for Proprietary Medicinal Products (CPMP) and International Conference on Harmonisation of Technical Requirements for Registration of Pharmaceuticals for Human Use (ICH): ICH Topic E8/Note for Guidance on general considerations for clinical trials. 1998;CPMP/ICH/291/95.

56 Directive 2001/20/EC of the European Parliament and of the Council of 4 April 2001 on the approximation of the laws, regulations and administrative provisions of the Member States relating to the implementation of Good Clinical Practice in the conduct of clinical trials on medicinal products for human use. OJ 2001;L121:34-44.

57 Commission Directive 2005/28/EC of 8 April 2005 laying down the principles and detailed guidelines for good clinical practice as regards investigational medicinal products for human use, as well as the requirements for authorisation of the manufacturing or importation of such products. OJ 2005;L91:13-19. 